\title{
Effect of fluoride exposure on bone metabolism indicators ALP, BALP, and BGP
}

\author{
Yu-e Song • Hao Tan $\cdot$ Ke-jian Liu • \\ Yu-zeng Zhang $\cdot$ Yun Liu $\cdot$ Cui-rong Lu • \\ Da-lin Yu $\cdot$ Jun Tu $\cdot$ Cai-yan Cui
}

Received: 16 November 2009/ Accepted: 2 September 2010/Published online: 2 October 2010

(c) The Japanese Society for Hygiene 2010

\begin{abstract}
Objective To analyze the changes in serum alkaline phosphatase (ALP) and bone alkaline phosphatase (BALP) activity and changes in osteocalcin (BGP) content following fluoride exposure and, thereby, determine the reference indications of fluoride-induced changes in bone metabolism. Methods In the animal study, rats were allowed free access to drinking water containing different concentrations $(10,150$, or $400 \mathrm{mg} / \mathrm{L})$ of sodium fluoride. Serum ALP and BALP activity and serum BGP content were assessed at three exposure time-points. In the spot study, serum ALP and BALP activity and serum BGP content were assessed in workers exposed to fluoride in their working environment for different periods of time.

Results Compared with the control group, on days 15 and 30 , the activity of serum ALP in the low- and medium-dose group was significantly higher $(p<0.05)$, while in the high-dose group it was significantly lower $(p<0.05)$. Only on day 30 was the activity of serum BALP in the mediumdose group significantly higher than that of the control group $(p<0.05)$. BGP content was lower in the high-dose group than in the control group $(p<0.05)$ on days 30 and 90 , but it was higher in the medium-dose group on day 90 . Compared with the control group, BGP content in the fluoride-exposed group was higher $(p<0.05)$. In the spot study, serum ALP activity and serum BGP content in the
\end{abstract}

Y. Song · H. Tan · K. Liu ( $₫) \cdot$ Y. Zhang $\cdot$ Y. Liu $\cdot$ C. Lu ·

D. $\mathrm{Yu} \cdot$ J. Tu $\cdot$ C. Cui

Department of Occupational and Environmental Health,

Tongji Medical College, Huazhong University of Science

and Technology, Wuhan 430030, Hubei, China

e-mail: 1kj484@sohu.com medium working-age group were higher than that in the short working-age group $(p<0.05)$. However, serum ALP activity and serum BGP content were lower in the long working-age group than in the medium working-age group $(p<0.05)$.

Conclusions Our results suggest that serum fluoride and urinary fluoride can be used as reference indications to provide an overall reflection of the body's fluoride-load and fluoride exposure level. Serum ALP activity and serum BGP content can be used as important reference indications for diagnosing bone metabolism changes resulting from fluoride exposure.

Keywords Sodium fluoride $\cdot$ Alkaline phosphatase . Bone alkaline phosphatase activity - Osteocalcium . Reference indications

\section{Introduction}

Fluorine is an essential trace element. Topical application of fluorine at high concentrations is frequently used for preventing dental caries, but prolonged excessive intake can lead to skeletal and/or dental fluorosis and to damage to the brain, heart, liver, renal system, and thyroid. A number of published studies have shown that fluorine affects the collagen metabolism of cartilage and bone. At the same dose, the clinical symptoms caused by fluorine are different due to the differences in exposure time. In view of these characteristics, we have studied the changes in relevant indicators of bone metabolism in rats (animal study) and humans (spot study) exposed to different doses of fluoride for different lengths of time. We determine the reference indications of fluoride exposure and provide a theoretical basis for the prevention and treatment of fluorosis. 


\section{Materials and methods}

\section{Animal experiments}

Fifty-two healthy male Wistar rats were selected from the Laboratory Animal Center of Tongji Medical College. The rats were provided food and water ad libitum for 3 days before the experiments. Four rats were selected randomly as group zero; the remaining 48 rats were randomly divided into three experimental groups and a control group, with each group comprising on average 12 animals. The experimental groups were given drinking water supplemented with different concentrations of fluorine in the form of sodium fluoride (Shanghai No. 3 Chemical Plant, Shanghai, PRC): low-dose fluoride $(10 \mathrm{mg} / \mathrm{L})$, middle-dose fluoride $(150 \mathrm{mg} / \mathrm{L})$, and high-dose fluoride $(400 \mathrm{mg} / \mathrm{L})$, respectively. The control group received tap water only in which the amount of fluorine was $0.18 \pm 0.05 \mathrm{mg} / \mathrm{L}$. On day 0 , the rats in the group zero were sacrificed and their serum collected for testing. Rats in the other four groups were fed and watered (sodium fluoride-supplemented drinking water or tap water) for up to 90 days. On each of days 15,30 , and 90 day, four rats from each of the exposure groups and from the control group were randomly chosen and sacrificed and their serum collected for testing.

Spot study

Eighty-six adult male workers at an aluminum factory in Hubei province, China, without liver, kidney, or bonerelated diseases were randomly asked to participate in the study. Fifty-eight of the participants were chosen from the Potroom (fluoride exposure group) and the remainder worked in a department where they were not exposed to fluoride (fluoride non-exposure group). Ambient air was collected by lime-paper sampling at the same time and place for 7 consecutive days, and the fluorine ion-selective electrode method was used for measuring the concentration of fluoride in the air. The 58 individuals in the fluoride exposure group were divided into three groups according to working-age: long working-age ( $>20$ years), medium working-age (10 years $<$ working-age $\leq 20$ years), and shortworking age ( $\leq 10$ years). Blood samples were collected after obtaining informed consent.

Detection of bone metabolism indicators

Blood was obtained from the sacrificed rats and the upper arm of the workers and serum was collected after $1 \mathrm{~h}$. The ion-selective electrode method was used to determine the fluorine content. Serum alkaline phosphatase (ALP) activity was detected using disodium phenyl phosphate and a kit from the Biotechnology Company of Jiancheng, serum bone alkaline phosphatase (BALP) activity was tested by heat denaturation, and serum osteocalcin (BGP) content was detected by radioimmunoassay (RIA) using a RIA kit (Beijing North Biotechnology Co, Beijing, PRC).

Statistical analysis

All data were presented as mean values with standard deviations (SD). Statistical tests for significance were performed using the one-way analysis of variance (ANOVA) and $t$ test with SPSS ver. 16.0 software (SPSS, Chicago, IL), employing the Student, Newman, Kuels (SNK) multiple range and least significant difference (LSD) procedures for between-group tests. Differences were considered to be statistically significant at $p<0.05$.

\section{Results}

Compared with the control, the content of urinary fluoride in rats of the high-, middle-, and low-dose (except for day 30 ) groups was significantly higher on days 15,30 , and 90 day $(p<0.05)$. Data are shown in Table 1.

The content of serum fluoride in rats of the three fluoride-exposure groups on days 15,30 , and 90 was significantly higher than that in rats of the control group $(p<0.05)$, with the exception of the low-dose group on day 90. When compared with the low-dose group, the content of serum fluoride in the middle- and high-dose

Table 1 Content of urinary fluoride in rats of the different sodium fluoride-exposure and control groups over time

\begin{tabular}{|c|c|c|c|c|c|c|}
\hline \multirow[t]{2}{*}{ Group } & \multirow{2}{*}{$\begin{array}{l}\text { Fluoride } \\
\text { concentration }(\mathrm{mg} / \mathrm{L})\end{array}$} & \multirow{2}{*}{$\begin{array}{l}\text { Number of } \\
\text { animals }\end{array}$} & \multicolumn{4}{|c|}{ Content of urinary fluoride $(\mathrm{mg} / \mathrm{L})$} \\
\hline & & & Day 0 & Day 15 & Day 30 & Day 90 \\
\hline High-dose & 400 & 4 & $11.70 \pm 4.12$ & $491.87 \pm 167.08^{*}$ & $419.35 \pm 189.98^{*}$ & $301.58 \pm 73.57 *$ \\
\hline Middle-dose & 150 & 4 & $11.70 \pm 4.12$ & $290.14 \pm 73.84^{*}$ & $115.07 \pm 21.22 *$ & $175.61 \pm 55.79 *$ \\
\hline Low-dose & 10 & 4 & $11.70 \pm 4.12$ & $29.42 \pm 17.17^{*}$ & $18.96 \pm 6.35$ & $28.96 \pm 14.69 *$ \\
\hline Control & 0.18 & 4 & $11.70 \pm 4.12$ & $10.14 \pm 3.60$ & $16.36 \pm 1.74$ & $12.61 \pm 4.31$ \\
\hline
\end{tabular}

$* p<0.05$ compared with the control

Values are given as the mean \pm standard deviation (SD) 
groups was significantly higher on days 15, 30, and 90 day $(p<0.05)$. It is noteworthy that the content of serum fluoride in the low- and middle-dose group decreased after day 15 , while in the high-dose group, it first increased first and then decreased with the prolonged exposure time (Table 2).

As shown in Table 3, compared with the control group, the activity of serum ALP was significantly higher in the low- and medium-dose groups on days 15 and 30 $(p<0.05)$, but significantly lower in the high-dose group on day $15(p<0.05)$. When compared with the low-dose group, the activity of serum ALP in the medium-dose group was lower on day 90.

Only in the middle-dose group on day 30 did the vitality of serum BALP show a significant difference $(p<0.05)$ (Table 4).

Compared with the control group, the content of BGP was lower in high-dose group on days 30 and 90 $(p<0.05)$, but it was higher in the medium-dose group on day 90. When compared with the low-dose group, the content of BGP of the medium-dose group on day 90 was also higher (Table 5).

Table 2 Content of serum fluoride in serum of rats of the different sodium fluoride-exposure and control groups over time

\begin{tabular}{lllllll}
\hline Group & $\begin{array}{l}\text { Fluoride } \\
\text { concentration } \\
(\mathrm{mg} / \mathrm{L})\end{array}$ & $\begin{array}{l}\text { Number of } \\
\text { animals }\end{array}$ & & \multicolumn{2}{l}{ Content of serum fluoride $(\mathrm{mg} / \mathrm{L})$} & \\
\cline { 5 - 7 } & & Day 0 & Day 15 & Day 30 & Day 90 \\
\hline High-dose & 400 & 4 & $0.11 \pm 0.04$ & $0.50 \pm 0.08^{*} \dagger$ & $0.95 \pm 0.50 \dagger$ & $0.53 \pm 0.11^{*} \dagger$ \\
Middle-dose & 150 & 4 & $0.11 \pm 0.04$ & $0.43 \pm 0.10^{*} \dagger$ & $0.32 \pm 0.11^{*} \dagger$ & $0.28 \pm 0.10^{*} \dagger$ \\
Low-dose & 10 & 4 & $0.11 \pm 0.04$ & $0.23 \pm 0.02^{*}$ & $0.15 \pm 0.04^{*}$ & $0.13 \pm 0.03$ \\
Control & 0.18 & 4 & $0.11 \pm 0.04$ & $0.12 \pm 0.02$ & $0.06 \pm 0.04$ & $0.10 \pm 0.05$ \\
\hline
\end{tabular}

$* p<0.05$ compared with the control

$\dagger p<0.05$ compared with the low-dose group

Values are given as the mean \pm SD

Table 3 Serum alkaline phosphatase activity in rats in the different sodium fluoride-exposure and control groups over time

\begin{tabular}{lllllll}
\hline Group & $\begin{array}{l}\text { Fluoride } \\
\text { concentration }(\mathrm{mg} / \mathrm{L})\end{array}$ & $\begin{array}{l}\text { Number } \\
\text { of animals }\end{array}$ & & \multicolumn{4}{l}{ Serum ALP activity (King units/100 mL) } \\
\cline { 5 - 7 } & & & Day 0 & Day 15 & Day 30 & Day 90 \\
\hline High-dose & 400 & 4 & $39.51 \pm 2.81$ & $33.05 \pm 5.21^{*}$ & $45.78 \pm 2.40^{*}$ & $32.26 \pm 2.77$ \\
Middle-dose & 150 & 4 & $39.51 \pm 2.81$ & $37.92 \pm 4.90$ & $55.50 \pm 2.15^{*}$ & $30.81 \pm 2.82 \dagger$ \\
Low-dose & 10 & 4 & $39.51 \pm 2.81$ & $45.13 \pm 1.67 *$ & $50.71 \pm 2.13$ & $35.75 \pm 3.84$ \\
Control & 0.18 & 4 & $39.51 \pm 2.81$ & $40.18 \pm 1.86$ & $50.50 \pm 1.59$ & $34.68 \pm 2.53$ \\
\hline
\end{tabular}

$* p<0.05$ compared with the control

$\dagger p<0.05$ compared with the low-dose group

Values are given as the mean $\pm \mathrm{SD}$

$A L P$ alkaline phosphatase

Table 4 Serum bone alkaline phosphatase activity in rats in the different sodium fluoride-exposure and control groups over time

\begin{tabular}{lllllll}
\hline Group & $\begin{array}{l}\text { Fluoride } \\
\text { concentration }(\mathrm{mg} / \mathrm{L})\end{array}$ & \multirow{2}{*}{$\begin{array}{l}\text { Number } \\
\text { of animals }\end{array}$} & & \multicolumn{4}{l}{ Serum BALP activity (King units/100 mL) } \\
\cline { 5 - 7 } & & & Day 0 & Day 15 & Day 30 & Day 90 \\
\hline High-dose & 400 & 4 & $21.93 \pm 3.31$ & $21.21 \pm 2.94$ & $25.57 \pm 3.58$ & $25.43 \pm 2.57$ \\
Middle-dose & 150 & 4 & $21.93 \pm 3.31$ & $21.34 \pm 2.92$ & $35.29 \pm 1.58^{*}$ & $25.13 \pm 3.63$ \\
Low-dose & 10 & 4 & $21.93 \pm 3.31$ & $27.99 \pm 4.67$ & $30.76 \pm 3.60$ & $29.81 \pm 3.19$ \\
Control & 0.18 & 4 & $21.93 \pm 3.31$ & $24.28 \pm 2.67$ & $30.29 \pm 2.29$ & $28.17 \pm 3.28$ \\
\hline
\end{tabular}

$* p<0.05$ compared with the control

Values are given as the mean $\pm \mathrm{SD}$

$B A L P$ bone alkaline phosphatase 
Table 5 Serum osteocalcin content in rats in the different sodium fluoride-exposure and control groups over time

\begin{tabular}{|c|c|c|c|c|c|c|}
\hline \multirow[t]{2}{*}{ Group } & \multirow{2}{*}{$\begin{array}{l}\text { Fluoride } \\
\text { concentration } \\
(\mathrm{mg} / \mathrm{L})\end{array}$} & \multirow{2}{*}{$\begin{array}{l}\text { Number of } \\
\text { animals }\end{array}$} & \multicolumn{4}{|c|}{ Content of serum BGP $(\mathrm{ng} / \mathrm{mL}))$} \\
\hline & & & Day 0 & Day 15 & Day 30 & Day 90 \\
\hline High-dose & 400 & 4 & $1.37 \pm 0.66$ & $1.31 \pm 0.30$ & $0.79 \pm 0.27 *$ & $0.63 \pm 0.11^{*}$ \\
\hline Middle-dose & 150 & 4 & $1.37 \pm 0.66$ & $1.08 \pm 0.61$ & $1.10 \pm 0.10$ & $1.32 \pm 0.29 * \dagger$ \\
\hline Low-dose & 10 & 4 & $1.37 \pm 0.66$ & $1.41 \pm 0.64$ & $0.91 \pm 0.10$ & $0.72 \pm 0.27$ \\
\hline Control & 0.18 & 4 & $1.37 \pm 0.66$ & $1.85 \pm 0.31$ & $1.20 \pm 0.16$ & $0.86 \pm 0.10$ \\
\hline
\end{tabular}

$* p<0.05$ compared with the control

$\dagger p<0.05$ compared with the low-dose group

Values are given as the mean $\pm \mathrm{SD}$

$B G P$ osteocalcin

Table 6 Serum fluoride, urinary fluoride, and age in the fluoride-exposed and control groups

\begin{tabular}{llllll}
\hline Group & $\begin{array}{l}\text { Number of } \\
\text { participants }\end{array}$ & Age (years) & Serum fluoride $(\mathrm{mg} / \mathrm{L})$ & Urinary fluoride $(\mathrm{mg} / \mathrm{L})$ & Air fluoride $\left(\mathrm{mg} / \mathrm{m}^{3}\right)$ \\
\hline Fluoride-exposed & 58 & $38.35 \pm 14.24$ & $0.46 \pm 0.22^{*}$ & $2.72 \pm 0.16^{*}$ & $2.08 \pm 1.01^{*}$ \\
Control & 28 & $39.70 \pm 13.90$ & $0.16 \pm 0.07$ & $0.63 \pm 0.16$ & $0.10 \pm 0.06$ \\
\hline
\end{tabular}

$* p<0.05$ compared with the control

Values are given as the mean $\pm \mathrm{SD}$

Table 7 Serum ALP and BALP activity and BGP content in the fluoride-exposed and control groups

\begin{tabular}{lllll}
\hline Group & $\begin{array}{l}\text { Number of } \\
\text { individuals }\end{array}$ & ALP (King units/100 mL) & BALP (King units/100 mL) & BGP (ng/mL) \\
\hline Fluoride-exposed & 58 & $6.70 \pm 0.55$ & $4.07 \pm 0.34$ & $6.94 \pm 2.14 *$ \\
Control & 28 & $6.20 \pm 0.40$ & $3.75 \pm 0.58$ & $5.49 \pm 2.22$ \\
\hline
\end{tabular}

$* p<0.05$ compared with the control

Values are given as the mean \pm SD

As shown in Tables 6, 7, and 8, compared with the control group, the content of serum fluoride, urinary fluoride, and BGP in the fluoride-exposure groups was higher $(p<0.05)$.

In the spot study, the activity of serum ALP and BGP content were higher in the medium working-age group than in the short working-age group $(p<0.05)$. However, compared with the medium working-age group, the content of BGP was lower in the long working-age group $(p<0.05)$.

\section{Discussion}

Fluorine is pro-bone element and mainly distributed in the hard tissues, such as bones and teeth. The accumulation of fluorine in the bone affects normal bone metabolism, causing bone metabolism and pathological changes and ultimately leading to fluoride-induced bone injury.
Research has shown that the concentration of urinary fluoride is related to, among others, nutritional status, diet, and renal function. A number of studies have shown that the concentration of serum fluoride provides more accurate information on fluoride metabolism and fluorine load levels in the human body than the level of urine fluoride $[1,2]$.

The results of our study also indicate that serum fluoride can accurately reflect the body burden levels of fluorine, thus suggesting that serum fluoride may possibly be used as a reference indicator of the body's fluoride load and fluoride exposure level.

The activity of ALP is a marker of bone formation. The results of our animal experiments show that in the low-dose group, serum ALP activity first and then decreased with prolonged exposure time. The trend in ALP was more complicated in the medium- and high-dose groups. From these results, we know that a low fluoride dose combined with a short exposure time increased serum ALP activity; however a high fluoride dose combined with a short 
Table 8 Serum ALP, BALP activity, and BGP content in the different working-age groups

\begin{tabular}{lllll}
\hline Group & $\begin{array}{l}\text { Number of } \\
\text { individuals }\end{array}$ & ALP (King units/100 mL) & BALP (King units/100 mL) & BGP (ng/mL) \\
\hline Long working-age & 24 & $6.80 \pm 0.74$ & $4.09 \pm 0.59$ & $5.97 \pm 1.79 \dagger$ \\
Middle working-age & 20 & $7.03 \pm 0.56^{*}$ & $4.24 \pm 0.65$ & $7.58 \pm 1.86^{*}$ \\
Short working-age & 14 & $6.40 \pm 0.34$ & $4.18 \pm 0.53$ & $6.27 \pm 1.08$ \\
\hline
\end{tabular}

$* p<0.05$ compared with the short working-age

$\dagger p<0.05$ compared with the middle working-age

exposure time resulted in an inhibition of serum ALP activity. This result is similar to that reported by Liu et al. [3]. Compared with the control group, ALP activity in the low-fluoride group had increased by day $15(p<0.05)$, which may have been due to a direct stimulation of fluorine. Also on day 15, ALP and BALP activity was higher in the medium-dose group than in the control $(p<0.05)$, suggesting that the accumulation of fluorine in bone could promote osteoblast mitosis, thereby affecting the viability of osteoblasts and indirectly modifying the content of the enzyme [4]. Not only is BALP a osteoblast surface marker, but it is also a marker of bone formation. Consequently, it can be concluded that fluorine is able to promote osteoblast differentiation and accelerate bone turnover, which are the specific pathological features of chronic fluorosis. However, ALP activity in the high-dose group was lower on days 15 and $30(p<0.05)$, suggesting that high-dose fluoride could directly inhibit enzyme activity or osteoblast activity.

Serum osteocalcin (BGP) content is a specific, sensitive sign of bone formation and also a sensitive and reliable indicator that reflects changes in bone metabolism. BGP of the bone matrix is released into the blood during bone resorption. Thus, BGP level is considered to be a specific biochemical indicator for judging bone turnover status. Our animal experiments revealed that, compared with the control, the content of BGP in the low-dose group had no statistical significance at all times, suggesting that low doses of fluoride did not lead to the excessive activity of osteoblasts. On day 90 , the content of BGP in the middle-dose group increased $(p<0.05)$, suggesting that fluorine-induced changes in osteoblast activity required a certain dose and exposure time; this result is consistent with results from other published studies $[5,6]$. BGP concentration in the high-dose group decreased on days 30 and $90(p<0.05)$, indicating that this dose of fluoride had had an inhibitory effect on osteoblasts, which is consistent with most published data [7, 8].

In human studies, most of the results published to date indicate the serum ALP activity increases with exposure to fluoride $[4,9,10]$. The level of serum ALP in individuals with skeletal fluorosis has been found to be significantly higher than that in a normal group [11].The results of our study show that the changes in the activity of ALP and
BALP in the fluoride-exposure group were not statistically significant $(p>0.05)$. We speculate that after a long period of fluoride exposure, the structure of the enzyme molecules change due to fluoride binding with the enzyme molecule, leading to increasing or decreasing activity of the enzyme, or fluorine exposure could reduce the content of $\mathrm{Cu}, \mathrm{Zn}$, $\mathrm{Mg}$, and other metal elements, reducing the binding capacity of the enzyme and, possibly, its activity. An interesting observation was that the activity of serum ALP in the medium working-age group was higher than that in the short working-age group $(p<0.05)$; this result deserves further study. Compared with the control group, the content of BGP in the fluoride-exposure group was higher $(p<0.05)$, which is consistent with the results reported by $\mathrm{Ma}$ et al. [12]. The content of BGP in the medium working-age group was higher $(p<0.05)$, but it was lower in the long working-age group $(p<0.05)$. We suggest that the accumulation of fluorine requires some time and that this process slows down with the extension of exposure time. In the early accumulation period, fluorine stimulates cells of the osteoblast lineage, thereby enhancing bone osteoblasts and accelerating bone turnover; thereafter, the activity of ALP and BGP content increase. However, in the late accumulation state, bone turnover slows down and BGP content decreases. Therefore, we consider that serum ALP activity and BGP content may be considered as reference indications of the bone metabolism changes in fluoride exposure.

In conclusion, changes in serum ALP and BALP activity BGP content are important reference indicators of fluoride exposure. We therefore suggest that serum fluoride, serum ALP activity, and BGP content may be important reference indications of fluoride exposure.

Acknowledgments This research was sponsored by the China National Nature Science Foundation (Grant no. 30671742).

\section{References}

1. Ehrnebo M, Ekstrand J. Occupational fluoride exposure and plasma fluoride levels in man. Int Arch Occup Environ Health. 1986;58(3):179-90. 
2. Kertesz P. Monitoring occupational fluoride exposure through urinary and salivary test. Fluoride. 1989;22(2):85-9.

3. Liu LZ, Sun DJ, Gao YH, Liu YQ, Yang XJ, Deng JY, et al. Activity of alkaline phosphatase and levels of calcium and phosphorus in serum of fluorosis associated with brick tea in areas of high altitude. Chin J Endemiol. 2005;24:9-10.

4. Huang H, Ba Y, Wu JJ, Li EW, Ma JG, Li SH, et al. Effects of the contents of $\mathrm{Ca}^{2+}$ and $\mathrm{Mg}^{2+}$ in drinking water on serum alkaline phosphatase in fluoride exposed population (in Chinese). J Zhengzhou Univ (Med Sci). 2007;42:55-7.

5. Miao Q, Xu M, Liu BC, You BR, Kang N. In vivo and in vitro study on the effect of excessive fluoride on type I collagen of rats. J Hygiene Res (in Chinese). 2002;31:145-7.

6. Tan H, Liu KJ, Lu CR, Zhang YZ, Zheng HY. Study on early diagnostic indexes of skeleton damage caused by fluoride (in Chinese). Ind Health Occup Dis. 2005;31:149-52.

7. Xle C, Zhang H, Yu MJ, He J, Zhang Z, Zhou LY. Change of bone $\gamma$-carboxyglutamic acid containing protein in the serum of rats at the initial stage of skeletal fluorosis caused by fluoride in coal. J Environ Health. 2005;22:406-9.
8. Gao YH, Fu SB, Sun H, Zhou LW, Wang Y, Yu J, et al. Dynamic analysis of effects of subchronic fluorosis on bone turnover in rats (in Chinese). Chin J Endemiol. 2005;24:288-90.

9. Wei Y, Cui LX. Study on relationship between contents of $\mathrm{Ca}^{2+}$ and $\mathrm{Mg}^{2+}$ in drinking water and activity of serum alkaline phosphatase in fluoride exposed group (in Chinese). J Med Forum. 2007;28:44-6.

10. Li KJ, Fu QZ, Guan ZJ. Effects on bone mineral density serum alkaline phosphatase and superoxide dismutase of fluoride exposed people (in Chinese). Ind Health Occup Dis. 2003;29: $293-4$.

11. Chen YKi, Tian PY, Ye JS, Mo KY, Yang XJ, Yu YJ. Determination of serum calcium phosphorus and alkaline phosphatase in the patients with coal burning skeletal fluorosis (in Chinese). J Hebei North Univ (medical edn). 2008;25:27-8.

12. Ma JX, Li MF, Song Y'E, Tu J, Liu FQ, Liu KJ. Serum osteocalcin and calcitonin in adult males with different fluoride exposures. Fluoride. 2009;42:133-6. 